\title{
Effect of epigallocatechin gallate on aluminum chloride-induced changes in behavior, biochemical parameters, and spermatogenesis of Sprague-Dawley rats
}

\author{
Subramani Parasuraman *1D, Brenda Ngu Yen Qin, Lam Chew Hui and James Yu Kar Beng
}

\begin{abstract}
Background: Epigallocatechin gallate (EGCG) acts as an antioxidant by preventing oxidative stress. The effect of EGCG on aluminum-induced testicular injury is not clear. Hence, the present study is planned to investigate the effect of EGCG on aluminum chloride ( $\mathrm{AlCl}_{3}$ )-induced changes in behavior, biochemical parameters, and spermatogenesis in male Sprague-Dawley rats. The rats were divided into six groups with six animals each. All the animals were administered with respective assigned treatment once daily for 28 days. The animals in groups I to VI were administered with drug vehicle, $\mathrm{AlCl}_{3}$, vitamin $\mathrm{C}, \mathrm{EGCG}$, vitamin $\mathrm{C}$, and $\mathrm{EGCG}$, respectively. The animals in groups $\mathrm{V}$ and $\mathrm{VI}$ were additionally challenged with $\mathrm{AlCl}_{3}(10 \mathrm{mg} / \mathrm{kg})$ immediately after vitamin $\mathrm{C}$ and $\mathrm{EGCG}$ administration, respectively. Changes in behavior were measured on day 1, 14 and 28 . At the end of the study, the blood sample was collected from all the animals, and the serum was separated and used for biochemical analysis. Later, the rats were subjected to bilateral orchiectomy; sperm was collected from the cauda epididymis for microscopic examination. Then, the animals were sacrificed, and the organs such as the brain, lungs, heart, liver, kidney, spleen, and testis were collected for organ weight analysis.

Results: The animal administered with $\mathrm{AlCl}_{3}$ showed a reduction in locomotor activity, grip strength, and escape latency time whereas vitamin $\mathrm{C}$ prevented the effect of $\mathrm{AlCl}_{3}$. But, EGCG did not show any significant changes in $\mathrm{AlCl}_{3}$-induced behavioral and biochemical changes. At the end of the study, vitamin $\mathrm{C}$ prevented $\mathrm{AlCl}_{3}$-induced behavioral and biochemical changes. The group of animals administered with $\mathrm{AlCl}_{3}$ showed a reduction in the number of spermatozoa whereas $\mathrm{AlCl}_{3}+$ vitamin $\mathrm{C}$ and $\mathrm{AlCl}_{3}+\mathrm{EGCG}$ did not show any significant changes in the number of spermatozoa when compared to the control group.
\end{abstract}

Conclusion: $\mathrm{EGCG}$ prevented $\mathrm{AlCl}_{3}$-induced reduction in epididymal sperm count of male rats and did not show any significant effect on $\mathrm{AlCl}_{3}$-induced changes in behavior and biochemical parameters, whereas vitamin $\mathrm{C}$ had an ameliorative effect on $\mathrm{AlCl}_{3}$-induced changes in behavior, biochemical parameter, and spermatogenesis.

Keywords: Antioxidant, Catechin, Escape latency time, Grip strength, Locomotor activity, Muscle coordination, Orchiectomy

\footnotetext{
* Correspondence: parasuphd@gmail.com; parasuraman@aimst.edu.my

Department of Pharmacology, Faculty of Pharmacy, AIMST University, 08100 Bedong, Kedah, Malaysia
}

\section{Springer Open}

(c) The Author(s). 2020 Open Access This article is licensed under a Creative Commons Attribution 4.0 International License, which permits use, sharing, adaptation, distribution and reproduction in any medium or format, as long as you give appropriate credit to the original author(s) and the source, provide a link to the Creative Commons licence, and indicate if changes were made. The images or other third party material in this article are included in the article's Creative Commons licence, unless indicated otherwise in a credit line to the material. If material is not included in the article's Creative Commons licence and your intended use is not permitted by statutory regulation or exceeds the permitted use, you will need to obtain permission directly from the copyright holder. To view a copy of this licence, visit http://creativecommons.org/licenses/by/4.0/. 


\section{Background}

Aluminum (Al) is the third most common element that can be found in the earth's crust and also found in soil, water, and air [1]. The physical and chemical properties of this element make it supreme for a variety of uses in food, drugs, consumer products, and water treatment processes. $\mathrm{Al}$ is a compound that has been incorporated into different kinds of products such as antacids, phosphate binders, buffered aspirins, vaccines, and allergen injections as well as into consumer products such as antiperspirants, first-aid antibiotic, antiseptics, and food additives [2]. In recent years, the potential adverse health effects of $\mathrm{Al}$ that are present in drinking water had raised concerns among the community.

Exposure to $\mathrm{Al}$ in drinking water is associated with health risks which can be acute and chronic toxicity. For acute toxicity, there is little indication that $\mathrm{Al}$ is acutely toxic by oral exposure, despite its widespread occurrence in foods, drinking water, and many antacid preparations [3]. There are no reported cases of acute $\mathrm{Al}$ poisoning of healthy individuals exposed to normal levels of $\mathrm{Al}$, which is below $0.2 \mathrm{mg} / \mathrm{L}$ [4]. Severe diseases of the nervous system such as Parkinson's dementia, amyotrophic lateral sclerosis, and Alzheimer's disease are associated with chronic $\mathrm{Al}$ toxicity [5]. High consumption of $\mathrm{Al}$ containing products will increase the concentration of this metallic element in the consumers' organs and damage their various tissues including the testicular tissues $[6,7]$. Krasovskil et al. have confirmed the gonadal toxicity of lead and aluminum chloride $\left(\mathrm{AlCl}_{3}\right)$ in guinea pigs and rats [8]. Al decreases sperm count, daily sperm production and sperm motility and low concentrations of $\mathrm{Al}$ in testes $(3.35 \mu \mathrm{g} / \mathrm{g})$ are sufficient to impair spermatogenesis and sperm quality [9]. $\mathrm{AlCl}_{3}$ also decreases the body weight, weights of testis or epididymis, number of normal sperm cells, sperm concentration and motility in experimental animals [10]. A significant decrease in fertility in female and male rats and the necrosis of spermatocytes/spermatids were found due to the accumulation of $\mathrm{Al}$ in the testis $[11,12]$. Accumulation of $\mathrm{Al}$ will also cause male reproductive toxicity, and this may be mediated through various mechanisms inducing oxidative stress, interfering with spermatogenesis and steroidogenesis, impairing cell signaling, disrupting the blood-testis barrier, and affecting the endocrine system [6].

In recent years, natural antioxidants are gaining interest in the management of diseases related to oxidative stress. Epigallocatechin gallate (EGCG) is one of the natural antioxidants; an active component of green tea can serve as an antioxidant and therapeutic agent [13]. EGCG is the ester of epigallocatechin and gallic acid and/or the major polyphenolic constituent, abundant in dried fresh leaves of the plant Camellia sinensis (family
Theaceae) [12]. C. sinensis/tea plant/green tea also contains other catechins such as (-)-epicatechin-3-gallate (ECG), (-)-epigallocatechin (EGC), (-)-epicatechin (EC), and (+)-catechin [10]. EGCG and other catechins are the phytoconstituents of green tea and responsible for its potential health benefits [11]. EGCG is claimed to have a powerful antioxidant effect and can decrease stress and inflammation. Highly reactive particles such as free radicals can cause oxidative damage to human cells, and overproduction of the radicals will cause oxidative stress. In this case, EGCG acts as an antioxidant agent by preventing oxidative stress and also suppresses the activity of pro-inflammatory chemicals [14]. Different kinds of chronic illnesses such as cancer, diabetes, and heart disease are related to stress and inflammation, and EGCG is useful in preventing diseases by acting as an antioxidant agent $[15,16]$. The effect of EGCG on Al-induced testicular injury is not clear. Hence, the present study is planned to investigate the effect of $\mathrm{EGCG}$ on $\mathrm{AlCl}_{3}$-induced changes in behavior, biochemical parameters, and spermatogenesis in male Sprague-Dawley (SD) rats.

\section{Methods}

\subsection{Chemicals}

Calcium chloride $\left(\mathrm{CaCl}_{2}\right)$, monopotassium phosphate $\left(\mathrm{KH}_{2} \mathrm{PO}_{4}\right)$, sodium lactate, and vitamin $\mathrm{C}$ were purchased from R\&M Marketing, Essex, UK. $\mathrm{AlCl}_{3}$ and glucose were purchased from Friendemann Schmidt Chemical, USA. Analytical-grade sodium chloride $(\mathrm{NaCl})$, potassium chloride $(\mathrm{KCl})$, magnesium sulfate $\left(\mathrm{MgSO}_{4}\right)$, and sodium bicarbonate $\left(\mathrm{NaHCO}_{3}\right)$ were purchased from Bendosen, Malaysia. Sodium pyruvate was purchased from Sigma Chemical, USA. EGCg green tea extract-400-mg capsules-were purchased from Now Foods, USA. Each capsule of EGGg contains $200 \mathrm{mg}$ of EGCG.

\subsection{Animals}

Healthy, adult, male SD rats with a weight of $180 \pm$ $20 \mathrm{~g}$ were used for the study. The rats were housed and maintained in large, spacious polyacrylic cages at ambient room temperature with a 12-h light/12-h dark cycle. The animals were fed with water and normal rat pellet diet ad libitum. The study was approved by the University Human and Animal Ethics Committee (AUAEC/FOP/2019/09), and the study was conducted according to the Animal Research Review Panel guidelines.

\subsection{Experimental design}

Healthy, adult male SD rats were used for the study. The animals were divided into six groups with six animals each as follows:

Group I: control 
Group II: $\mathrm{AlCl}_{3}(10 \mathrm{mg} / \mathrm{kg})$

Group III: Vitamin C $(200 \mathrm{mg} / \mathrm{kg})$

Group IV: EGCG $(50 \mathrm{mg} / \mathrm{kg})$

Group V: $\mathrm{AlCl}_{3}(10 \mathrm{mg} / \mathrm{kg})+$ vitamin C $(200 \mathrm{mg} / \mathrm{kg})$

Group VI: $\mathrm{AlCl}_{3}(10 \mathrm{mg} / \mathrm{kg})+\mathrm{EGCG}(50 \mathrm{mg} / \mathrm{kg})$

The doses of vitamin C and EGCG were selected based on the available literature $[17,18] . \mathrm{AlCl}_{3}(10 \mathrm{mg} / \mathrm{kg})$ was used to induce oxidative stress [19]. Vitamin C, EGCG, and $\mathrm{AlCl}_{3}$ were dissolved in distilled water for injection and administered intraperitoneally.

All the animals were administered with respective assigned treatment once daily for 28 days. The animals in groups I to VI were administered with drug vehicle, $\mathrm{AlCl}_{3}$, vitamin C, EGCG, vitamin C, and EGCG, respectively. The animals in groups $\mathrm{V}$ and VI were additionally challenged with $\mathrm{AlCl}_{3}(10 \mathrm{mg} / \mathrm{kg})$ immediately after vitamin $C$ and EGCG treatment. The changes in body weight and behavior were measured at regular intervals [20]. At the end of the study, the blood sample was collected from all the animals, and the serum was separated. The serum samples were used for biochemical analysis. Later, the rats were subjected to bilateral orchiectomy; sperm was collected from the cauda epididymis for microscopic examination [21, 22]. Then, the animals were sacrificed, and the organs such as the brain, lungs, heart, liver, kidney, spleen, and testis were collected for organ weight analysis.

\subsection{Body weight analysis}

The body weight (BW) of each rat in each group was recorded initially and at 3 days intervals. The change in BW was calculated.

\subsection{Behavior and muscular activities}

At regular intervals, behavioral (locomotor activity), muscular coordination (rotarod and wire grip test), and memory function (Morris water maze test) were evaluated.

\subsubsection{Locomotor activity}

The activity of the rats was recorded in a rat activity cage (actophotometer) which is constructed with an acrylic cage and 8 beams of infrared light along both the $x$ and $y$-axes. The activity of each rat was monitored at room temperature over $10 \mathrm{~min}$.

\subsubsection{Muscle coordination (rotarod) test}

The rat was placed on a rotarod with a speed of 20 RPM. The time between rat maintains on the rotarod and when it fall was recorded. The procedure was repeated for each rat.

\subsubsection{Hanging wire grip test}

The string is made up of metallic wire and suspended in mid-air about $30 \mathrm{~cm}$ height from the ground. The rat was placed on the center of the wire, and the time taken to fall, i.e., "fall on time," was noted.

\subsubsection{Morris water maze test}

The water navigation test is employed as a method to test spatial learning and memory parameters to evaluate spatial learning and memory functions. The training was taken place for 3 consecutive days, with four consecutive trials/day for each experimental rat at the inter-trial interval of $30 \mathrm{~min}$. In the pre-study training sessions, if the animals failed to escape on the platform within 180 $\mathrm{s}$, they will be excluded from the study.

The Morris water maze consists of a round pool, filled with tap water, which is close to $23-26^{\circ} \mathrm{C}$, at a depth of $0.3-0.4 \mathrm{~m}$. The pool was divided into four hypothetical quadrants, with an escape platform placed $1 \mathrm{~cm}$ below the water surface at the center. Four different starting points for rats were placed around the perimeter of the pool. The test was performed from day 24 onwards at day intervals. Escape latency time (ELT) to locate the hidden platform in the water maze was noted as an index of learning.

\subsection{Quality evaluation of semen}

\subsubsection{Determination of sperm motility}

At the end of the study, sperm samples were collected from the cauda epididymis. The cauda epididymis was isolated and placed in a petri dish contacting Biggers, Whitten, and Whittingham (BWW) [which consists of $95 \mathrm{mM} \mathrm{NaCl}, 4.8 \mathrm{mM} \mathrm{KCl}, 1.3 \mathrm{mM} \mathrm{CaCl}, 1.2 \mathrm{mM}$ $\mathrm{MgSO}_{4}, 1.2 \mathrm{mM} \mathrm{KH_{2 }} \mathrm{PO}_{4}, 20 \mathrm{mM}$ sodium lactate, $5 \mathrm{mM}$ glucose, $0.25 \mathrm{mM}$ sodium pyruvate, and $25 \mathrm{mM}$ $\mathrm{NaHCO}_{3}, \mathrm{pH}$ 7.4] medium to allow the sperm to swim (swim-up technique). An appropriate volume of spermatozoa was transferred to a preheated cell count plate. From a total of 200 spermatozoa, the active ones were observed using a microscope to calculate sperm motility [23].

\subsubsection{Determination of sperm count}

After completing the determination of sperm motility, the rest of the sperm suspension was quickly transferred to $60^{\circ} \mathrm{C}$ water bath for $5-10 \mathrm{~min}$ to induce loss activation of sperm and then carefully added to the cell count plate. The number of spermatozoa was calculated using the red blood cell counting method [24].

\subsection{Biochemical analysis}

At the end of the experiment, a few milliliters $(\mathrm{mL})$ of the blood sample was collected in the micro-centrifuge tube through retro-orbital plexus and the serum was 
separated by centrifuging at $3000 \mathrm{RPM}$ for $20 \mathrm{~min}$. The serum samples were used for biochemical marker estimation such as glucose, aspartate aminotransferase (AST), alanine aminotransferase (ALT), alkaline phosphatase (ALP), creatinine and, urea, and lipid parameters such as total cholesterol (TC), triglyceride (TGL), and high-density lipoprotein (HDL) using the Reflotron Plus biochemical analyzer (Roche Diagnostics, Germany) with the help of commercially available Reflotron strips. Very low-density lipoprotein (VLDL) and cholesterol ratio were calculated mathematically [20].

\subsection{Gross pathology and organ weight analysis}

At the end of the experiment, all the experimental animals were sacrificed under mild ether anesthesia followed by cervical dislocation. The animals were dissected, and the gross pathology was observed. The organs such as the brain, lungs, heart, liver, kidney, spleen, and testis were harvested; absolute organ weights were measured, and relative organ weights were calculated.

\subsection{Statistical analysis}

Data were represented as mean \pm standard error of the mean (SEM). Statistical analysis was carried out using one-way ANOVA followed by Turkey's post-hoc test. A value of $P<0.05$ shall be considered to be significant.

\section{Results}

\subsection{Effects of EGCG on body weight variations}

The effects on the body weights of $\mathrm{AlCl}_{3^{-}}$, vitamin C-, EGCG-, $\mathrm{AlCl}_{3}+$ vitamin C-, and $\mathrm{AlCl}_{3}+$ EGCGadministered male rats were summarized in Fig. 1. At the end of the study, $\mathrm{AlCl}_{3}$ - and $\mathrm{AlCl}_{3}+$ EGCGadministered animals showed a significant reduction in body weight when compared to the control group. The animals, administered with vitamin C and EGCG alone, did not show any significant changes in regular body weight gain when compared to the control group.

\subsection{Effects of EGCG on the behavior of the rats}

The animals administered with $\mathrm{AlCl}_{3}$ and $\mathrm{AlCl}_{3}+\mathrm{EGCG}$ showed significant decreases in locomotor activity (Fig. 2), grip strength (Fig. 3), and ELT (Fig. 4) when compared to the control group, whereas the animals administered with vitamin C and EGCG alone did not show any significant changes when compared to the control group. In the rotarod experiment, the animals administered with $\mathrm{AlCl}_{3}$ + EGCG only showed significant decreases in muscular strength (Fig. 5), whereas the other groups did not show any significant changes in the "fall on time" when compared to the control group.

\subsection{Effects of ECGC on biochemical parameters}

In the biochemical analysis, the animals administered with $\mathrm{AlCl}_{3}$ and $\mathrm{AlCl}_{3}+$ EGCG showed significant increases in the levels of glucose, AST, ALT, urea, and creatinine when compared to the control group (Table 1). The animals administered with vitamin C and EGCG did not show any significant changes in the levels of glucose, AST, ALT, ALP, urea, and creatinine when compared to the control group. In lipid analysis (TC, TGL, HDL, and VLDL), no significant changes were observed in the animals administered with $\mathrm{AlCl}_{3}$, vitamin $\mathrm{C}$, EGCG, $\mathrm{AlCl}_{3}+$ vitamin $\mathrm{C}$, and $\mathrm{AlCl}_{3}+$ EGCG when compared to the control group (Table 2).

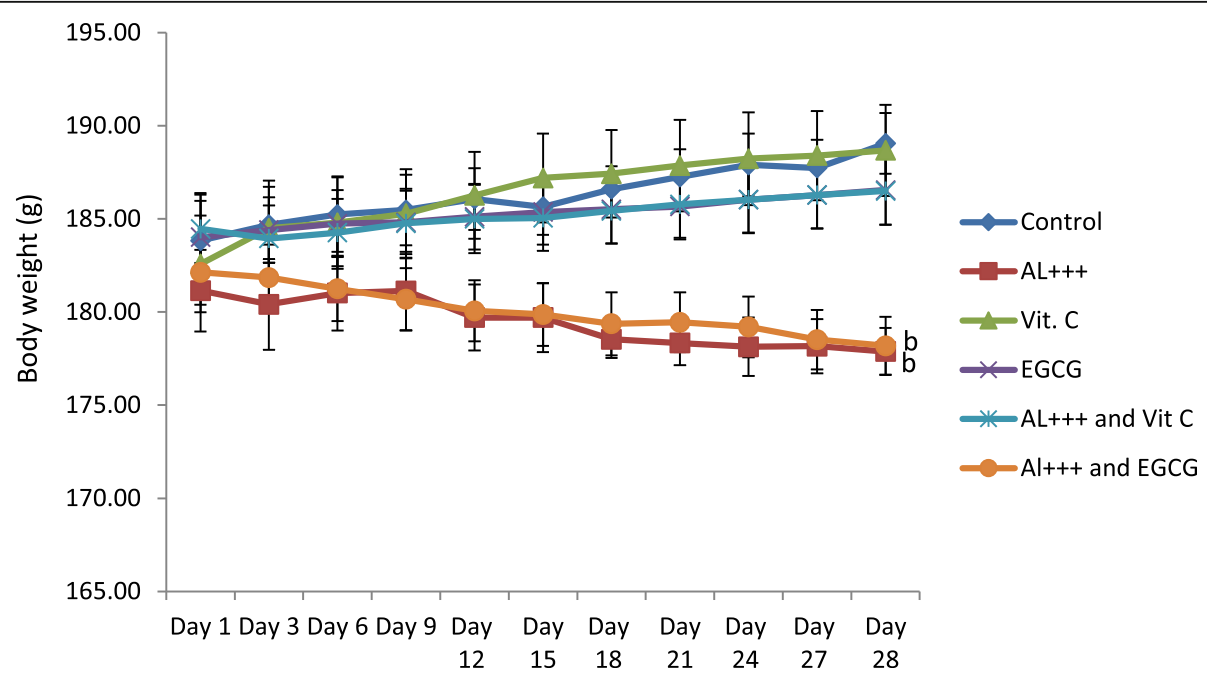

Fig. 1 Effect of aluminum, vitamin C, EGCG, aluminum + vitamin C, and aluminum + EGCG on regular body weight growth of animals. Values are expressed as mean \pm SEM $(n=6)$. ${ }^{b} P<0.01$ compared with control (one-way ANOVA followed by Tukey's post-hoc test) 


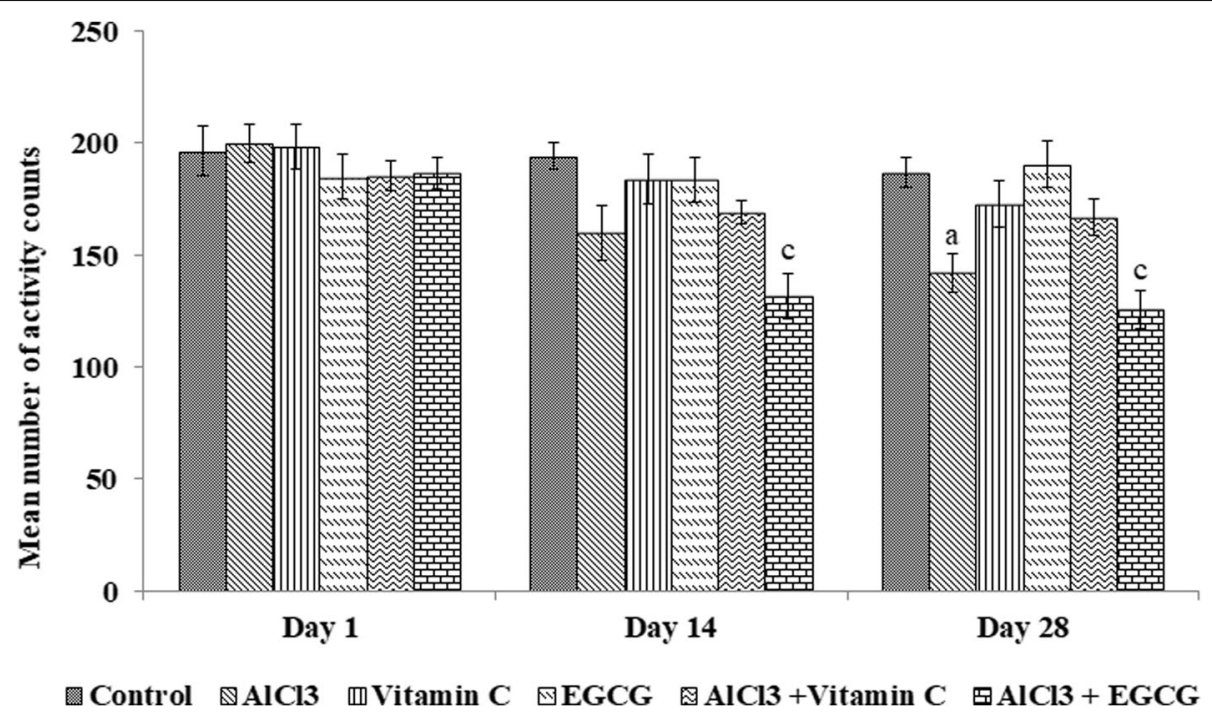

Fig. 2 Effect of EGCG on locomotor activity of the rats. Values are expressed as mean \pm SEM $(n=6)$. ${ }^{\mathrm{a}} P<0.05$ and ${ }^{\mathrm{c}} P<0.001$ compared with control (one-way ANOVA followed by Tukey's post-hoc test)

\subsection{Effects of EGCG on organ weight of rats}

No changes in gross pathology between the treated and control groups were observed. The animals administered with $\mathrm{AlCl}_{3}$, vitamin $\mathrm{C}$, EGCG, $\mathrm{AlCl}_{3}+$ vitamin $\mathrm{C}$, and $\mathrm{AlCl}_{3}+$ EGCG did not show any significant changes in absolute and relative organ weights of the brain, lung, heart, liver, kidney, spleen, and testis when compared to the control group.

\subsection{Effects of EGCG on quality of semen}

The sperms were observed under a light microscope. Reduction in the number of viable sperm cells was observed in the animals administered with $\mathrm{AlCl}_{3}$ whereas the other groups did not show any significant changes when compared to the control group (Fig. 6). The animals administered with $\mathrm{AlCl}_{3}$ showed a significant reduction in the number of sperm cells compared to the

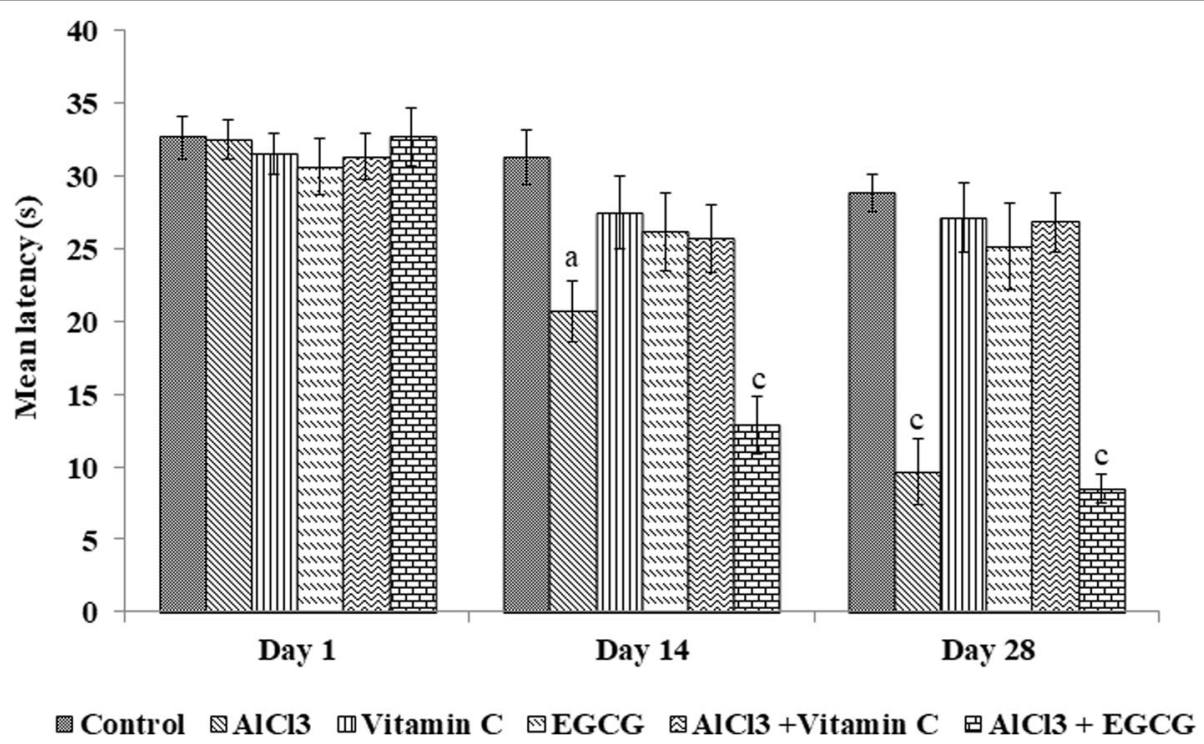

Fig. 3 Effect of EGCG on wire grip strength of the rats. Values are expressed as mean \pm SEM $(n=6) .{ }^{\text {a }} p<0.05$ and ${ }^{c} p<0.001$ compared with control (one-way ANOVA followed by Tukey's post-hoc test) 


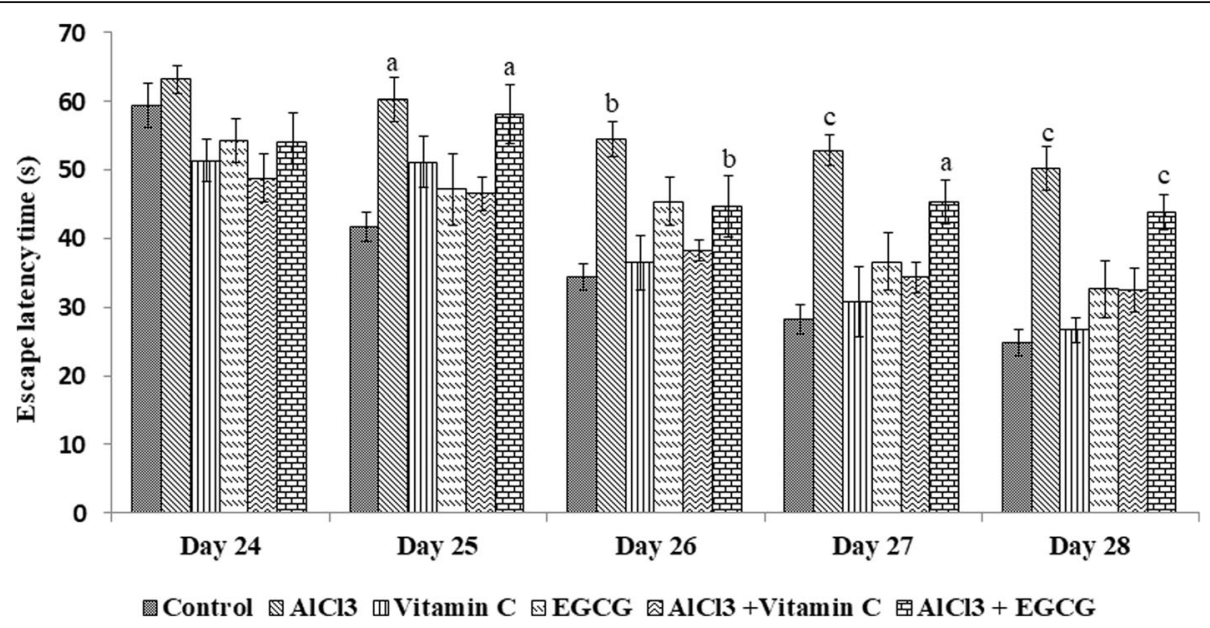

Fig. 4 Effect of EGCG on escape latency time of the rats. Values are expressed as mean $\pm \operatorname{SEM}(n=6) .{ }^{a} P<0.05,{ }^{b} P<0.01$, and ${ }^{c} P<0.001$ compared with control (one-way ANOVA followed by Tukey's post-hoc test)

control group. The animals administered with $\mathrm{AlCl}_{3}+$ vitamin $\mathrm{C}$ or EGCG showed a quantitative reduction in sperm count, but the results were not significant (Table 3). The weight of the epididymis caput/corpus and the epididymis cauda did not show any significant variation compared to the control group.

\section{Discussion}

In recent years, natural antioxidants are gaining interest in the management of diseases related to oxidative stress. EGCG is a natural antioxidant; an active component of green tea can serve as an antioxidant and therapeutic agent [13]. There were a number of proven effects of EGCG on human pathological and physiological processes, and its mechanisms in various systems and diseases are reported elsewhere [25, 26]. Male reproductive toxicity occurs due to the accumulation of $\mathrm{Al}$, and these are due to various mechanisms such as inducing oxidative stress, interfering with spermatogenesis and steroidogenesis, impairing cell signaling, disrupting the blood-testis barrier, and affecting the endocrine system [6].

In the present study, the effect of EGCG on $\mathrm{AlCl}_{3}$-induced changes in behavior, biochemical parameters, and spermatogenesis was studied. The animals administered with $\mathrm{AlCl}_{3}$ showed a decrease in body weight, and the same was reported elsewhere [27, 28].

The animals administered with $\mathrm{AlCl}_{3}$ showed a significant reduction in locomotor activity and grip strength whereas the animals co-administered with vitamin $\mathrm{C}$ prevented behavior alteration induced by $\mathrm{AlCl}_{3}$.

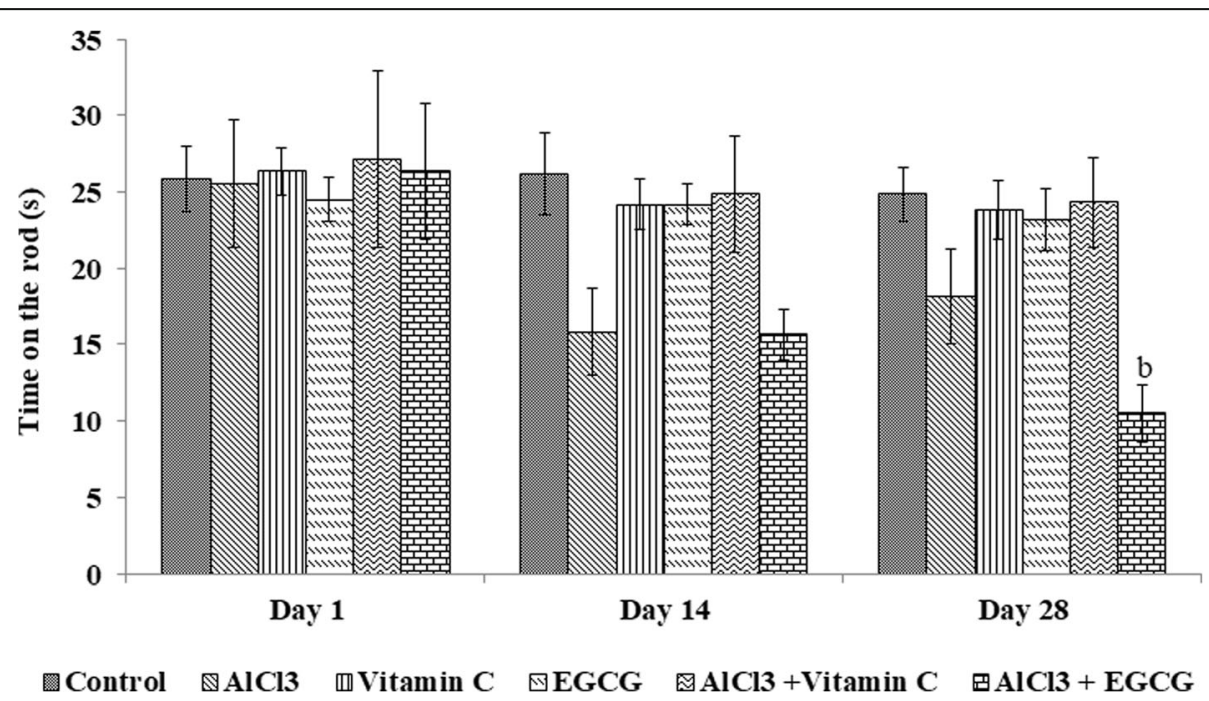

Fig. 5 Effect of EGCG on muscular coordination of the rats. Values are expressed as mean \pm SEM $(n=6)$. ${ }^{b} p<0.05$ compared with control (oneway ANOVA followed by Tukey's post-hoc test) 
Table 1 Effect of EGCG on biochemical parameters of the rats

\begin{tabular}{lllllll}
\hline Group & Glucose $(\mathbf{m m o l} / \mathbf{L})$ & AST $(\mathbf{U} / \mathbf{L})$ & ALT $(\mathbf{U} / \mathbf{L})$ & ALP (U/L) & Urea (mg/dL) & Creatinine (mg/dL) \\
\hline Control & $5.8 \pm 0.28$ & $83.6 \pm 2.70$ & $47.1 \pm 3.91$ & $104.33 \pm 6.01$ & $20.33 \pm 1.49$ & $0.29 \pm 0.01$ \\
$\mathrm{AlCl}_{3}$ & $8.05 \pm 0.50^{*}$ & $113.33 \pm 9.00^{*}$ & $76.1 \pm 8.40^{*}$ & $125.83 \pm 9.76$ & $38.0 \pm 2.98^{* * *}$ & $0.437 \pm 0.04^{* *}$ \\
Vitamin C & $5.93 \pm 0.29$ & $78.17 \pm 5.59$ & $51.17 \pm 5.71$ & $103.67 \pm 6.18$ & $21.6 \pm 1.33$ & $0.26 \pm 0.02$ \\
EGCG & $5.83 \pm 0.23$ & $87.83 \pm 3.83$ & $48.33 \pm 3.11$ & $110.33 \pm 5.89$ & $21.33 \pm 1.76$ & $0.32 \pm 0.01$ \\
$\mathrm{AlCl}_{3}+$ vitamin C & $6.78 \pm 0.69$ & $80.83 \pm 4.44$ & $46.83 \pm 4.70$ & $106.33 \pm 3.48$ & $22.83 \pm 2.40$ & $0.327 \pm 0.02$ \\
$\mathrm{AlCl}_{3}+$ EGCG & $8.55 \pm 0.72^{* *}$ & $122.67 \pm 11.38^{* *}$ & $82.67 \pm 6.17^{* *}$ & $127.17 \pm 7.33$ & $40.33 \pm 2.51^{* * *}$ & $0.483 \pm 0.01^{* * *}$ \\
\hline
\end{tabular}

Values are expressed as mean \pm SEM $(n=6)$. ${ }^{*} P<0.05,{ }^{* *} P<0.01$, and ${ }^{* * *} P<0.001$ compared with control (one-way ANOVA followed by Tukey's post-hoc test)

Nampoothiri et al. reported the reduction of locomotor activity with $\mathrm{AlCl}_{3}$ administration, indicating the central nervous system depressant effect of chronic $\mathrm{Al}$ exposure [29]. The impaired spatial memory and behavioral function were observed in $\mathrm{AlCl}_{3}$-administered animals which indicate the development of neurotoxicity [30]. Lal et al. also demonstrated decreased locomotor activity, increased brain lipid peroxidation, and decreased brain Mg-ATPase and Nak-ATPase in rats exposed to aluminum (500 mg Al/L in drinking water) daily for 180 days [31]. In the rotarod experiment, $\mathrm{AlCl}_{3}$ coadministered with EGCG showed a significant reduction in muscular strength when compared to the control group, and this may be due to high $\mathrm{Al}$ levels in the brain [32]. In this study, EGCG did not show any neuroprotective effect against $\mathrm{AlCl}_{3}$-induced neurotoxicity. But the neuroprotective effect of EGCG was demonstrated elsewhere against quinolinic acid, D-galactose, and hypoxiaischemia-induced neurotoxicity [33-35].

The animals treated with $\mathrm{AlCl}_{3}$ increased ELT in the Morris water maze test, and this test is more specific for hippocampal function. The rats administered with $\mathrm{AlCl}_{3}$ took a longer time to reach the visible platform in the Morris water maze test compared to the control group from day 25 onwards, and this indicates memory deficits and reduced spatial memory [28]. EGCG coadministration failed to reverse the $\mathrm{AlCl}_{3}$-induced memory deficits.

In the biochemical analysis, the animals administered with $\mathrm{AlCl}_{3}$ showed significant increases in the levels of glucose, AST, ALT, urea, and creatinine compare to the control group, and EEST failed to prevent the $\mathrm{AlCl}_{3}$ effects on biochemical parameters. Biomarkers such as AST, ALT, and ALP were used to check liver functions, and urea and creatinine were used to check the renal functions. The elevated levels of these biomarkers indicating that the animals administered with $\mathrm{AlCl}_{3}$ have the risk of liver and kidney damage. $\mathrm{AlCl}_{3}$ is a known hepatotoxicant, and it may increase the levels of liver enzymes by reducing the electron transport chain complex I-V activities and adenosine triphosphate levels and disturb the mitochondrial DNA transcript [36]. The nephrotoxicity induced by $\mathrm{AlCl}_{3}$ is may be due to the accumulation of $\mathrm{Al}$ in the kidney, eventually resulting in renal failure [37]. The animals administered with vitamin C, EGCG, and $\mathrm{AlCl}_{3}$ + vitamin $\mathrm{C}$ did not show any abnormalities in biochemical parameters. In both in vitro and in vivo experiments, EGCG showed significant hepatoprotective effect bromobenzene and alcohol-induced hepatotoxicity. Kagaya et al. studied the effect of EGCG on bromobenzene-induced hepatotoxicity in rat hepatocyte cells and reported hepatoprotective $0.02 \mathrm{mM}$ EGCG $+0.02 \mathrm{mM}$ zinc. In this study, EGCG alone did not show any hepatoprotective activity at $0.02 \mathrm{mM}$ against bromobenzene-induced hepatotoxicity [38]. Zhang et al. studied the effect of EGCG on alcohol-induced hepatotoxicity in HepG2 cell line and male Kunming mice. In both experiments, EGCG alleviated the changes induced by alcohol in a dose-dependent manner, and this may be mediated via its antioxidant activity [39]. Bao and Peng demonstrated the nephroprotective effect of EGCG in a chronic kidney disease model (decreased serum creatinine levels) [40]. But, in this study, EGCG did not show any significant hepatoprotective and nephroprotective

Table 2 Effect of EGCG on the lipid profile of the rats

\begin{tabular}{llllll}
\hline Group & TC $(\mathbf{m g} / \mathbf{d L})$ & TGL $(\mathbf{m g} / \mathbf{d L})$ & HDL $(\mathbf{m g} / \mathbf{d L})$ & VLDL $(\mathbf{m g} / \mathbf{d L})$ & Cholesterol ratio \\
\hline Control & $104.83 \pm 4.15$ & $84.6 \pm 2.71$ & $18.5 \pm 1.52$ & $16.93 \pm 0.54$ & $5.88 \pm 0.58$ \\
Aluminum & $105.83 \pm 4.00$ & $78.67 \pm 4.78$ & $16.83 \pm 0.54$ & $15.73 \pm 0.95$ & $6.32 \pm 0.31$ \\
Vit. C & $108.1 \pm 3.07$ & $84.67 \pm 4.73$ & $19.67 \pm 0.802$ & $16.93 \pm 0.95$ & $5.54 \pm 0.25$ \\
EGCG & $103.6 \pm 4.84$ & $80.83 \pm 2.926$ & $19.167 \pm 1.56$ & $16.167 \pm 0.59$ & $5.54 \pm 0.419$ \\
Aluminum + vit. C & $102.8 \pm 2.71$ & $83.33 \pm 3.77$ & $17.83 \pm 1.27$ & $16.67 \pm 0.75$ & $5.861 \pm 0.29$ \\
Aluminum + EGCG & $104.83 \pm 3.95$ & $98.83 \pm 3.95$ & $15.67 \pm 0.76$ & $19.7 \pm 0.79$ & $6.74 \pm 0.33$ \\
\hline
\end{tabular}

Values are expressed as mean \pm SEM $(n=6)$ 


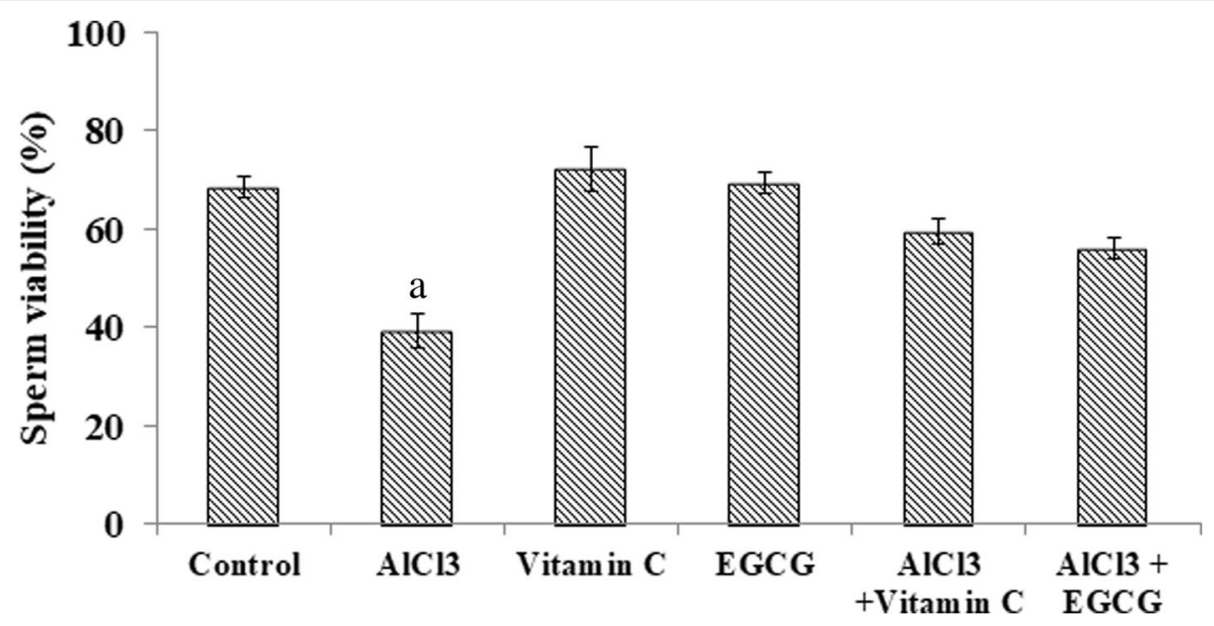

Fig. 6 Effect of EGCG on percentage sperm viability. Values are expressed as mean \pm SEM $(n=6)$. ${ }^{a} p<0.05$ compared with control (one-way ANOVA followed by Tukey's post-hoc test)

activities against $\mathrm{AlCl}_{3}$-induced Hepato- and nephrotoxicity. In lipid analysis, no significant changes in the levels of TC, TGL, and HDL were observed in all experimental groups when compared to the control group. Yang et al. studied the effect of EGCG and ECCG co-administered with caffeine in obese rats and reported both low dose of ECCG $(40 \mathrm{mg} / \mathrm{kg})$ and caffeine $(20 \mathrm{mg} / \mathrm{kg})$ has a mild anti-obesity effect and a high dose of EGCG $(160 \mathrm{mg} / \mathrm{kg})$ and combination (ECCG $[40 \mathrm{mg} / \mathrm{kg}]+$ caffeine [20 mg/ $\mathrm{kg}]$ ) exhibits superior curative effect [41].

Analysis of organ weight was used in toxicology studies for the identification of potentially harmful effects of chemicals. In this experiment, no significant changes in absolute and relative organ weight were observed in all experimental groups when compared to the control group.

The reduction in sperm viability is observed in $\mathrm{AlCl}_{3}-$ administered animals. Hadi and Deaibil also reported a decrease in the percentage of sperm viability in $\mathrm{AlCl}_{3}$ administered animals, and this may be due to mitochondrial dysfunction [42]. In epididymal sperm count analysis, only those administered with $\mathrm{AlCl}_{3}$ showed a significant reduction in sperm count. Cheraghi et al. also reported the effect of $\mathrm{AlCl}_{3}$ on sperm count, and in his study, the $\mathrm{AlCl}_{3}$-administered group showed $>50 \%$ reduction in the number of sperm cells compared to the control group [18]. The quality of the sperm including motility and viability is also affected by $\mathrm{Al}$ via the Nrf-2/ HO-1 signaling pathway $[18,43]$. In this study, the animals administered with $\mathrm{AlCl}_{3}+$ vitamin $\mathrm{C}$ and $\mathrm{AlCl}_{3}+$ EGCG showed a qualitative reduction in the number of sperm cells when compared to the control group, but the results were not significant.

\section{Conclusion}

EGCG did not show any significant effect on $\mathrm{AlCl}_{3}$-induced changes in behavior (locomotor activity, grip strength, escape latency time) and biochemical parameters, but it prevented $\mathrm{AlCl}_{3}$-induced reduction in epididymal sperm count of male rats. However, vitamin C had shown the ameliorative effect on $\mathrm{AlCl}_{3}$-induced changes in behavior, biochemical parameters, and spermatogenesis of rats.

Table 3 Effect of EGCG on sperm count and weight of the epididymis caput and epididymis cauda in SD rats

\begin{tabular}{llll}
\hline & Epididymal sperm count $(\times \mathbf{1 0} / \mathbf{m L})$ & Weight of the epididymis caput/corpus $(\mathbf{g})$ & Weight of the epididymis cauda $(\mathbf{g})$ \\
\hline Control & $17.17 \pm 1.58$ & $0.73 \pm 0.01$ & $0.48 \pm 0.02$ \\
$\mathrm{AlCl}_{3}$ & $10.33 \pm 0.95^{*}$ & $0.65 \pm 0.04$ & $0.39 \pm 0.02$ \\
Vitamin C & $16.67 \pm 1.26$ & $0.70 \pm 0.02$ & $0.46 \pm 0.02$ \\
$\mathrm{EGCG}$ & $16.50 \pm 1.52$ & $0.72 \pm 0.01$ & $0.47 \pm 0.02$ \\
$\mathrm{AlCl}_{3}+$ vitamin C & $13.67 \pm 1.38$ & $0.71 \pm 0.01$ & $0.46 \pm 0.03$ \\
$\mathrm{AlCl}_{3}+\mathrm{EGCG}$ & $11.67 \pm 1.12$ & $0.67 \pm 0.01$ & $0.47 \pm 0.01$ \\
\hline
\end{tabular}

Values are expressed as mean \pm SEM $(n=6) .{ }^{*} P<0.05$ compared with control (one-way ANOVA followed by Tukey's post-hoc test) 


\section{Supplementary information}

The online version contains supplementary material available at https://doi. org/10.1186/s43088-020-00079-3.

Additional file 1. The ARRIVE Guidelines Checklist. (PDF 1066 kb)

\section{Abbreviations}

AChE: Acetylcholinesterase; Al: Aluminum; $\mathrm{AlCl}_{3}$ : Aluminum chloride; ALP: Alkaline phosphatase; ALT: Alanine aminotransferase; AST: Aspartate aminotransferase; BW: Body weight; $\mathrm{CaCl}_{2}$ : Calcium chloride; DNA: Deoxyribonucleic acid; EC: (-)-Epicatechin; ECG: (-)-Epicatechin-3gallate; EGC: (-)-Epigallocatechin; EGCG: Epigallocatechin gallate; ELT: Escape latency time; HDL: High-density lipoprotein; $\mathrm{KCl}$ : Potassium chloride; $\mathrm{KH}_{2} \mathrm{PO}_{4}$ : Monopotassium phosphate; $\mathrm{MgSO}_{4}$ : Magnesium sulfate; $\mathrm{NaCl}$ : Sodium chloride; $\mathrm{NaHCO}_{3}$ : Sodium bicarbonate; RPM: Revolutions per minute; SD rats: Sprague-Dawley rats; SEM: Standard error of the mean; TC: Total cholesterol; TGL: Triglyceride; TNF-alpha: Tumor necrosis factoralpha; VLDL: Very low-density lipoprotein

\section{Acknowledgements}

$\mathrm{Nil}$

\section{Authors' contributions}

Subramani Parasuraman drafted the hypothesis for the current work and contributed to the protocol development, result analysis, manuscript preparation, and review. Brenda Ngu Yen Qin, Lam Chew Hui, and James Yu Kar Beng are the undergraduate students and they carried out the laboratory work, involved in manuscript and presented the thesis to the faculty. The authors read and approved the final manuscript.

\section{Funding}

Nil

\section{Availability of data and materials}

Not applicable

\section{Ethics approval and consent to participate}

The study was approved by the AIMST University Human and Animal Ethics Committee (AUAEC/FOP/2019/09), and the study was conducted according to the Animal Research Review Panel guidelines.

\section{Consent for publication}

Not applicable.

\section{Competing interests}

The authors declare that they have no competing interests.

Received: 14 May 2020 Accepted: 6 October 2020

Published online: 21 December 2020

\section{References}

1. Angelova I, Ivanov I, Venelinov T, Lazarova S (2019) Occurrence of aluminium in urban water supply and sewerage systems. Int Multidiscip Sci GeoConference: SGEM 19(5.1):501-508

2. ATSDR (2008) Toxicological profile for aluminium. United States Department of Health and Human Services, Public Health Service, Agency for Toxic Substances and Disease Registry, Atlanta

3. WHO Aluminium (2008) International Programme on Chemical Safety (Environmental Health Criteria 194). World Health Organization, Geneva

4. Veríssimo Ml, Gomes MT (2008) Aluminium migration into beverages: are dented cans safe? Sci Total Environ 405(1-3):380-388

5. Health Canada (1993) Guidelines for Canadian drinking water quality. Water treatment principles and applications: a manual for the production of drinking water. Health Canada, Environmental Health Directorate, Ottawa

6. Berihu BA (2015) Histological and functional effect of aluminium on male reproductive system. Int J Pharm Sci Res 6(8):1122-1132

7. Guo CH, Lin CY, Yeh MS, Hsu GS (2005) Aluminium-induced suppression of testosterone through nitric oxide production in male mice. Environ Toxicol Pharmacol 19(1):33-40
8. Krasovskiĭ G, Vasukovich LY, Chariev OG (1979) Experimental study of biological effects of leads and aluminium following oral administration. Environ Health Perspect 30:47-51

9. Martinez CS, Escobar AG, Uranga-Ocio JA, Peçanha FM, Vassallo DV, Exley C et al (2017) Aluminum exposure for 60days at human dietary levels impairs spermatogenesis and sperm quality in rats. Reprod Toxicol 73:128-141.

10. Zhu YZ, Sun H, Fu Y, Wang J, Song M, Li M et al (2014) Effects of subchronic aluminum chloride on spermatogenesis and testicular enzymatic activity in male rats. Life Sci 102(1):36-40.

11. Nagle DG, Ferreira D, Zhou YD (2006) Epigallocatechin-3-gallate (EGCG): chemical and biomedical perspectives. Phytochemistry. 67(17):1849-1855

12. Ahn WS, Yoo J, Huh SW, Kim C-K, Lee J-M, Namkoong SE et al (2003) Protective effects of green tea extracts (polyphenon E and EGCG) on human cervical lesions. Eur J Cancer Prev 12:383-390

13. Jin Y, Xi C, Qin J, Yong J (2019) Molecular pathways, green tea extract, (-)-epigallocatechin gallate, and ocular tissue. In: Handbook of nutrition, diet, and the eye. Academic Press, Cambridge, pp 303-320

14. Kawaguchi K, Matsumoto T, Kumazawa Y (2011) Effects of antioxidant polyphenols on TNF-alpha-related diseases. Curr Top Med Chem 11(14): 1767-1779

15. Eng QY, Thanikachalam PV, Ramamurthy S (2018) Molecular understanding of epigallocatechin gallate (EGCG) in cardiovascular and metabolic diseases. J Ethnopharmacol 210:296-310

16. Othman Al, El-Sawi MR, El-Missiry MA, Abukhalil MH (2017) Epigallocatechin3-gallate protects against diabetic cardiomyopathy through modulating the cardiometabolic risk factors, oxidative stress, inflammation, cell death and fibrosis in streptozotocin-nicotinamide-induced diabetic rats. Biomed Pharmacother 94:362-373

17. Giordano V, Albuquerque RP, Amaral NP, Chame CC, Souza FD, Apfel MÍ (2012) Supplementary vitamin C does not accelerate bone healing in a rat tibia fracture model. Acta Ortop Bras 20(1):10-12

18. Cheraghi E, Golkar A, Roshanaei K, Alani B (2017) Aluminium-induced oxidative stress, apoptosis and alterations in testicular tissue and sperm quality in Wistar rats: ameliorative effects of curcumin. Int J Fertil Steril 11(3): 166-175

19. Yang $X, Y$ Yuan $Y$, Niu Q. [Effects of aluminium chloride on the methylation of app in hippocampal of rats]. Wei Sheng Yan Jiu. 2016;45(3):345-9, 355 Chinese.

20. Parasuraman S, Hoong SS, Christapher PV, Zou LN, De Wei DL, Loshini S, Ching TH, Leong CH (2019) Effect of ethanolic extract of leaves of Solanum trilobatum on scopolamine-induced memory impairment in Sprague Dawley rats. J Pharm Negat Results 10:41-46

21. Othman MS, Nada A, Zaki HS, Abdel Moneim AE (2014) Effect of Physalis peruviana L. on cadmium-induced testicular toxicity in rats. Biol Trace Elem Res 159(1-3):278-287

22. Squadrito F, Micali A, Rinaldi M, Irrera N, Marini H, Puzzolo D et al (2017) Polydeoxyribonucleotide, an adenosine-A2(A) receptor agonist, preserves blood testis barrier from cadmium-induced injury. Front Pharmacol 7:537

23. He L, Li P, Yu LH, Li L, Zhang Y, Guo Y et al (2018) Protective effects of proanthocyanidins against cadmium-induced testicular injury through the modification of Nrf2-Keap1 signal path in rats. Environ Toxicol Pharmacol $57: 1-8$

24. He L, Li P, Yu LH, Li L, Zhang Y, Guo Y, Long M, He JB, Yang SH (2018) Protective effects of proanthocyanidins against cadmium-induced testicular injury through the modification of Nrf2-Keap1 signal path in rats. Environ Toxicol Pharmacol 57:1-8

25. Chu C, Deng J, Man Y, Qu Y (2017) Green tea extracts epigallocatechin-3gallate for different treatments. Biomed Res Int 2017:5615647

26. Siddiqui IA, Malik A, Adhami VM, Asim M, Hafeez BB, Sarfaraz S et al (2008) Green tea polyphenol EGCG sensitizes human prostate carcinoma LNCaP cells to TRAlL-mediated apoptosis and synergistically inhibits biomarkers associated with angiogenesis and metastasis. Oncogene. 27(14):2055-2063

27. Pandey G, Jain GC (2017) Aluminium chloride-induced testicular effects in rats: a histomorphometrical study. Asian J Appl Sci Tech 1(9):46-52

28. Prema A, Thenmozhi AJ, Manivasagam T, Essa MM, Akbar MD, Akbar M (2016) Fenugreek seed powder nullified aluminium chloride induced memory loss, biochemical changes, $A \beta$ burden and apoptosis via regulating Akt/GSK3 $\beta$ signaling pathway. PLoS One 11(11):e0165955

29. Nampoothiri M, John J, Kumar N, Mudgal J, Nampurath GK, Chamallamudi MR (2015) Modulatory role of simvastatin against aluminium chloride- 
induced behavioural and biochemical changes in rats. Behav Neurol 2015: 210169

30. Auti ST, Kulkarni YA (2019) Neuroprotective effect of cardamom oil against aluminum induced neurotoxicity in rats. Front Neurol 10:399

31. Lal B, Gupta A, Murthy RC, Ali MM, Chandra SV (1993) Aluminum ingestion alters behaviour and some neurochemicals in rats. Indian J Exp Biol 31:30-35

32. Colomina MT, Roig JL, Torrente M, Vicens P, Domingo JL (2005) Concurrent exposure to aluminium and stress during pregnancy in rats: effects on postnatal development and behavior of the offspring. Neurotoxicol Teratol 27(4):565-574

33. Jang S, Jeong HS, Park JS, Kim YS, Jin CY, Seol MB et al (2010)

Neuroprotective effects of (-)-epigallocatechin-3-gallate against quinolinic acid-induced excitotoxicity via PI3K pathway and NO inhibition. Brain Res 1313:25-33

34. He M, Zhao L, Wei MJ, Yao WF, Zhao HS, Chen FJ (2009) Neuroprotective effects of (-)-epigallocatechin-3-gallate on aging mice induced by Dgalactose. Biol Pharm Bull 32(1):55-60

35. Sutherland BA, Shaw OM, Clarkson AN, Jackson DN, Sammut IA, Appleton I (2005) Neuroprotective effects of (-)-epigallocatechin gallate following hypoxia-ischemia-induced brain damage: novel mechanisms of action FASEB J 19(2):258-260

36. Xu F, Liu Y, Zhao H, Yu K, Song M, Zhu Y, Li Y (2017) Aluminum chloride caused liver dysfunction and mitochondrial energy metabolism disorder in rat. J Inorg Biochem 174:55-62

37. Al Dera HS (2016) Protective effect of resveratrol against aluminum chloride induced nephrotoxicity in rats. Saudi Med J 37(4):369-378

38. Kagaya N, Kawase M, Maeda H, Tagawa Yl, Nagashima H, Ohmori H, Yagi K (2002) Enhancing effect of zinc on hepatoprotectivity of epigallocatechin gallate in isolated rat hepatocytes. Biol Pharm Bull 25(9):1156-1160

39. Zhang X, Wu Z, Weng P (2014) Antioxidant and hepatoprotective effect of (-)-epigallocatechin 3-O-(3-O-methyl) gallate (EGCG3"Me) from Chinese oolong tea. J Agric Food Chem 62(41):10046-10054

40. Bao H, Peng A (2016) The green tea polyphenol (-)-epigallocatechin-3gallate and its beneficial roles in chronic kidney disease. J Transl Med 4(3): 99-103

41. Yang Z, Zhu MZ, Zhang YB, Wen BB, An HM, Ou XC, Xiong YF, Lin HY, Liu ZH, Huang JA (2019) Coadministration of epigallocatechin-3-gallate (EGCG) and caffeine in low dose ameliorates obesity and nonalcoholic fatty liver disease in obese rats. Phytother Res 33(4):1019-1026

42. Hadi AH, Deaibil HB (2020) Effect of royal jelly on sperm parameters in aluminum-treated male rats. J Appl Tissue Eng 7(1):1-10.

43. Güvenç M, Cellat M, Gökçek I, Arkalı G, Uyar A, Tekeli IO, Yavaş I (2019) Tyrosol prevents $\mathrm{AlCl} 3$ induced male reproductive damage by suppressing apoptosis and activating the Nrf-2/HO-1 pathway. Andrologia 52:e13499

\section{Publisher's Note}

Springer Nature remains neutral with regard to jurisdictional claims in published maps and institutional affiliations.

\section{Submit your manuscript to a SpringerOpen ${ }^{\circ}$ journal and benefit from:}

- Convenient online submission

- Rigorous peer review

- Open access: articles freely available online

- High visibility within the field

- Retaining the copyright to your article

Submit your next manuscript at $\boldsymbol{\nabla}$ springeropen.com 